\title{
Erectile Dysfunction Associated with Psychoactive Substances
}

\author{
Bang-Ping Jiann* \\ Division of Urology, Department of Surgery, Kaohsiung Veterans General Hospital, Kaohsiung, Taiwan
}

\begin{abstract}
Psychoactive substances are believed to be aphrodisiac; but in reality they have deleterious effects on all the aspects of sexual function. The purpose of this article is to review and summarize the available scientific literature on the impact of psychoactive substances, including alcohol, tobacco and illicit drugs on erectile dysfunction (ED) in men. Almost all of them have been reported to be associated with ED. These substances may exert their inhibitory effect on erection through their effects on central neurotransmitter pathways (serotogenic, adrenergic or dopaminergic). Besides, some also may exhibit vasoconstricting properties (cocaine), impair endothelium function (nicotine) or suppress the release of luteinizing hormone from the pituitary, resulting in hypogonadism (morphine) to induce ED. The relationship between ED and psychoactive substances is attributed not only to pharmacological effects, but also to psychological and social reactions to substance dependence. Whether withdrawal from the substances could restore erectile function remains unknown. However, human and animal studies demonstrated that the effects of neurological damage from chronic substance abuse are long-lasting. This information of sexual consequence of the substances will be of great general interest and may serve as a powerful tool to healthcare providers.
\end{abstract}

Keywords: Erectile dysfunction; Psychoacitve drug; Alcohol; Tobacco; Street drugs

\section{Introduction}

Psychoactive substances (drugs) are substances that have the ability to change an individual's consciousness, mood or thinking process and are associated with dose tolerance and dependence. The consumption of the substances is categorized as licit (legal) and illicit (illegal) use. The licit ones include (i) caffeine, commonly used in the form of coffee, tea and many soft drinks; (ii) nicotine, currently most often used by smoking cigarettes; and (iii) alcohol, used in the form of beer, wine and distilled spirits. Their consumption is legal for whatever purpose the con-

Accepted for Publication: November 19, 2008

*Corresponding author: Bang-Ping Jiann, Division of Urology, Department of Surgery, Kaohsiung Veterans General Hospital, Phone: 886-7-3422121 ext 3010, FAX: 886-7-3455064, E-mail: bpjiaan@vghks.gov.tw sumer chooses. The illicit ones, such as heroin, amphetamine, 3,4-methylenedioxymethamphetamine (MDMA) and marijuana are highly addictive that most nations have bound themselves to outlaw their trade and non-medical use. Despite the prohibitions, illicit use of psychoactive substances is fairly wide spread in many societies. Use of illicit drugs is to be expected because of their pleasurable effects as well as peer pressure and the social context of their use. Because taking caffeinated substance is relatively harmless, it is not considered in this review.

Substance use and dependence cause a significant burden to individuals and societies throughout the world. The World Health Organization 2002 indicated that $8.9 \%$ of the total burden of disease worldwide in 2000 came from the use of psychoactive substances, tobacco accounting for $4.1 \%$, alcohol $4 \%$, and illicit drugs $0.8 \%{ }^{1}$ 
The main harmful effects resulting from substance use can be divided into four categories: (i) chronic health effects, e.g. liver cirrhosis in alcoholism, lung cancer and emphysema due to cigarette smoking; (ii) acute biological health effects, e.g. causalities and car accidents associated with drug use; (iii) acute social problem, e.g. a break in a relationship or an arrest; and (iv) chronic social problems, e.g. defaults in working life or in family roles. ${ }^{2}$

\section{Physiology and Pathophysiology of Penile Erection}

Erectile dysfunction (ED) is one of common sexual dysfunctions in adult males, defined as inability to obtain or maintain penile erection sufficient for satisfactory sexual performance. ${ }^{3}$ Erection is a complex neurovascular phenomenon that requires an intact psychosocial, neural and vascular component. Neural regulation of the penile vasculature is not only limited to the cavernous arteries but also involves smooth muscle of the trabecula and endothelium of the sinusoids. ${ }^{4}$ Endothelial cells within the penis produce nitric oxide $(\mathrm{NO})$ with the synthases, i.e., the neuronal, endothelial and inducible types. ${ }^{5-7}$ The endothelium is recognized as a highly active metabolic and endocrine organ involved in control of the systemic vasculature. Although NO produced by the endothelium may not be the primary mediator of smooth muscle relaxation during erection, NO synthase is an important determinant of cardiovascular homeostasis. It has a critical role in cell survival, blood vessel remodeling, atherosclerosis prevention and the inhibition of programmed cell death or apoptosis. ${ }^{8,9}$ Disease states such as smoking, which are thoughts to impair endothelial NO synthase, may have significant long-term effects on the health of the corpus cavernosum. ${ }^{10}$

The central nervous system (CNS) controls erectile function through dopaminergic and serotonergic system with the former exhibiting facilitative effect ${ }^{11}$ and the latter inhibitory. ${ }^{12}$ Testosterone (T) plays an essential role in normal male development as well as in the maintenance of many male characteristics, including muscle mass and strength, bone density, libido, potency, and spermatogenesis. Animal studies demonstrated that NO production is regulated by androgens. ${ }^{13}$ It is shown that androgens exert a direct effect on penile tissue to maintain erectile function, and androgen deficiency produces metabolic and structural imbalance in the corpus cavernosum, which results in veno-occlusive dysfunction and ED. ${ }^{13}$ Several classes of medications and recreational drugs have been linked to the manifestation of ED. ${ }^{14,15}$

\section{Effect of Psychoactive Substances on Erectile Function}

Psychoactive drugs exhibit their adverse effects either through central inhibitory neuroendocrine mechanisms and/or local neurovascular actions, or they have an impact on the hormonal milieu (Table 1). ${ }^{16-18}$

Table 1. Summary of characteristics of psychoactive substances and mechanism of interfering with erectile function

Psychoactive Characteristics and mechanism of interfering with agent erectile dysfunction

Ethanol Increasing the inhibitory activity of GABA-A receptor and decreasing the excitatory activity of glutamate receptor in CNS

Suppressing the sex axis and resulting in hypogonadism

Nicotine Vasoconstricting effect Increasing oxidative stress and resulting in endothelial dysfunction

Heroin A derivative of morphine

An illegal, highly addictive and CNS depressant Inhibiting the release of luteinizing hormone from the pituitary

Redirection of blood away from the genitals

Amphetamine A potent and highly addictive psychostimulant Enhancing the release and blocking the reuptake of dopamine and norepinephrine

MDMA A ring-substituted derivative of amphetamie Enhancing the release of serotonin, norepinephrine and dopamine

Cocaine A CNS and PNS stimulant with anesthetic and vasoconstricting action Inhibiting the reuptake of neurotransmitters

Marijuana Derived from the cannabis sativa plant Changes in CNS and cardiovascular system

GABA, gamma-aminobutyric acid; CNS, central nervous system; PNS, peripheral nervous system. 


\section{Alcohol}

The consumption of alcohol often precedes sexual activity and alcohol is commonly believed to be a powerful sexual facilitator and aphrodisiac due to its disinhibition properties. ${ }^{19}$ In humans, the acute behavioral effects of ethanol vary between individuals according to many factors such as dose, rate of drinking, gender, body weight, blood alcohol level and the time since the previous dose. Ethanol has biphasic behavioral effects. At low doses, the first effects that are observed are heightened activity and disinhibition. At higher doses, cognitive, perceptual and motor functions become impaired. Effects on mood and emotions vary greatly from person to person. ${ }^{20,21}$

Ethanol increases the inhibitory activity mediated by gamma-aminobutyric acid-A (GABA-A) receptors and decreases the excitatory activity mediated by glutamate receptors. ${ }^{22}$ GABA-A receptor activation mediates many of the behavioral effects of ethanol including motor incoordination, anxiolysis and sedation. ${ }^{23}$ As blood alcohol level rises, GABA action increases, thereby decreasing the flow of information from the brain to the spinal cord and causing sedation. These two mechanisms of action may be related to the general sedative effect of alcohol and impairment of memory during periods of intoxication. ${ }^{22}$ Imaging studies of brain metabolism show that alcohol decreases metabolic activity in occipital brain regions and increases metabolism in the left temporal cortex. ${ }^{24}$

In addition to the effects on CNS receptors, alcohol inhibits the hypothalamic-pituitary-adrenal axis and reduced the release of gonadotropin from the pituitary. The chronic abuse of alcohol may cause testicular atrophy, inhibition of $\mathrm{T}$ production and inhibition of spermatogenesis, apart from its direct oxidative toxicity. ${ }^{25,26}$

Consuming small amount of alcohol is unlikely to have an immediate short-term impact on a person's sexual response. As the amount of alcohol a person consumes increases, their physiological response to sexual stimulation decreases. ${ }^{20}$ Chronic and long-term alco- hol use directly or indirectly affects nearly every organ system in the body. Research on male alcoholics has found that greater quantity, frequency, and duration of drinking are associated with ED, inhibited libido and retarded ejaculation. ${ }^{19}$ O'Farrell et al. found that alcoholic men had over three times the prevalence of serious ED (i.e., at least $25 \%$ of the time) of demographically similar nonalcoholic men. ${ }^{27}$ Mandell et al. interviewed 44 alcoholic men and found that 59\% experienced ED during periods of heavy drinking and $84 \%$ reported some sexual dysfunction related to alcohol abuse. ${ }^{28}$ Another study by Snyder and Karacan measured nocturnal penile tumescence in a sample of 26 alcoholic men going through detoxification. They found that alcoholic men were more likely to have fewer, slower, and less rigid nocturnal erections than a nonalcoholic comparison group. ${ }^{29}$

Fahrner's follow-up study in 101 male alcoholics demonstrated that the percent of alcoholics reporting sexual dysfunction was not significantly reduced after nine months of abstinence although $\mathrm{T}$ level could return to normal..$^{30} \mathrm{O}^{\prime}$ Farrell et al. found that while alcoholism treatment reduced experiences of $\mathrm{ED}$, levels of ED among these alcoholics in recovery remained much higher than that of nonalcoholic men. ${ }^{27}$ The research from Lemere et al. suggested that many alcoholics suffered from ED even after years of sobriety, possibly due to the permanent neurological damage caused by long-term alcohol use. ${ }^{31}$

\section{Tobacco}

Smoking is a ubiquitous activity: more than 5,500 billion cigarettes are manufactured annually and there are 1.2 billion smokers in the world. This number is expected to increase to 2 billion by $2030 .^{32}$ Although tobacco contains thousands of substances, nicotine is the one most frequently associated with dependence. Acute doses of nicotine can produce alteration of mood, although daily users are substantially less sensitive to such effects than non-users, suggesting the presence of tolerance. $^{33}$ 
The impact of smoking on sexual function can be easily explained as nicotine is a potent vasoconstrictor. Blood nicotine level also rises after smoking, and this may increase the sympathetic tone in the penis, interfering with the relaxation of intracorporeal smooth muscle. ${ }^{34}$ Wolf and Shulman concluded that the changes of endothelium-derived relaxing factor, $\mathrm{NO}$, prostaglandin, prostacycline and thromboxane might contribute to smoking-induced ED. ${ }^{35}$

Tengs and Osgood performed a meta-analysis of literature over the last 20 years and revealed that $40 \%$ of impotent men were current smokers compared with $28 \%$ of men in the general population. ${ }^{36}$ McVary et al. comprehensively reviewed the literature and found that there were strong parallels and shared risks among smoking, coronary artery disease, atheroscleoris and ED. Their study also showed that smoking might increase the likelihood of moderate or complete ED two-fold and that there was a constant relationship of smoking and endothelial disease. ${ }^{10}$

A 9-year-interval follow-up study of Massachusetts Male Aging Study found that cigarette smoking at baseline almost doubled the likelihood of moderate or complete ED at follow-up (24\% vs. 14\%, adjusted for age and covariates, $\mathrm{p}=0.01){ }^{37}$ Bortolotti et al. reported risk factor of ED on 9,670 diabetic men who were categorized as: never smokers (30\%), current smokers (30\%), or ex-smokers $(40 \%)$. The results demonstrated that odds ratio $(\mathrm{OR})$ of $\mathrm{ED}$ for current smokers and ex-smokers was $1.4(95 \%$ CI $1.3 \sim 1.6)$ and $1.5(95 \%$ CI $1.3 \sim 1.6)$, respectively, compared to never smokers and the duration and intensity of smoking habit was associated with an increased risk of ED. ${ }^{38}$

Cigarette smoking is proved to be an independent risk factor for ED and may act either synergistically or additively with other risk factors. Mirone et al. conducted a cross-sectional study on the prevalence and risk factors for ED in 2,010 men in Italy. The ORs of ED in smokers, in comparison with never smokers, were respectively 2.4, 2.0 and 1.7 in men with no history of any cardiovascular disease, diabetes and neuropathy, but respectively $1.0,1.0$ and 1.2 in those with a history of the conditions. ${ }^{39}$

\section{Illicit Drugs}

Illicit drugs were taken as aphrodisiacs to enhance sexual performance or pleasure. The available researches suggested most illicit drugs imposed some adverse effects on penile erection, sexual desire and ejaculation latency in males, but the actual effects were not fully understood. ${ }^{40}$ Meanwhile, substance abuse was reported to be one of the most common contributing factors of ED in men aged less than 40 years $^{41}$ and recognizing the impact of illicit drugs on sexual function is useful for health care providers. Besides, knowing the drug-related sexual effects may be a motivation for some abusers to cease drug abuse. ${ }^{42}$ Gaps are supposed to exist in the research because most of previous studies about the impact of illicit drugs on sexual function adopted simple questions to evaluate sexual function, lacked controls and were based on small case numbers. ${ }^{40}$

\section{1) Opioids}

Opiate drugs are compounds that are extracted from the poppy seed. These drugs opened the way to the discovery of the endogenous opioid system in the brain. ${ }^{43}$ The term "opioids" includes "opiates" as well as semisynthetic and synthetic compounds (e.g. heroin and morphine) with similar properties. Intravenous injection of opioids produced a warm flushing of the skin and sensation described by users as a "rush"; however, the first experience with opiates can also be unpleasant, and can involve nausea and vomiting. ${ }^{44}$ Opioids have euphorogenic, analgesic, sedative, and respiratory depressant effects and are regarded as highly addictive substance. Opioid receptors and peptides are strongly expressed in the CNS. ${ }^{45}$ Three opioid receptors (mu, delta and kappa) are identified to mediate activity of both exogenous opioids (drugs) and endogenous opioid peptides. ${ }^{46}$ Acting on the CNS, long-term use of opiates impacts the neuroendocrine system and leads to the inhibition of gonadotropin-releasing hormone. ${ }^{47}$ This may 
result in decreased sexual desire and decreased $\mathrm{T}$ levels in men. Opioids' action on the CNS is thought to also cause the redirection of blood away from the genitals, which may contribute to ED (Table 1). ${ }^{17}$

In regular heroin users, decreased libido has been reported in the majority of addicts, ED in 39 48\% and delayed ejaculation in over $50 \%$ of the addicts. ${ }^{48,49}$ Palha and Esteves reported there was a significant decrease in weekly sexual intercourse and masturbatory activity in 101 heroin male addicts compared with healthy controls. ${ }^{42}$ Jiann assessed the prevalence of ED in heroin mono-drug users by validated International Index of Erectile Function questionnaire. Of the 276 males with heroin mono-use, $44.2 \%$ reported to have ED with an OR of ED of 4.8 (95\% CI: $2.9 \sim 7.8$ ), compared to the non-addict controls (Table 2). ${ }^{50}$ Heroin users had the highest prevalence of ED than the others, being attributed to the CNS inhibition and high addiction properties of heroin..$^{50}$

Chronic heroin abuse depresses testicular function through the inhibition of release of LH from the pituitary and the hormonal changes returned promptly to normal after withdrawal. ${ }^{51}$ Whether erectile function could be restored needs further study. Hypersexuality episodes may be observed in men experiencing opiate withdrawal, with spontaneous erections and nocturnal ejaculation. ${ }^{52}$ Men with methadone maintenance treat- ment also demonstrated a higher prevalence of ED due to hypogonadism and depression. ${ }^{48,53}$

\section{2) Amphetamine}

Amphetamine, methamphetamine, and other amphetamine analogs are synthetic drugs that increase CNS activity by stimulating the release and/or blocking the reuptake of the neurotrasmitters dopamine and norepinephrine (Table 1). ${ }^{40}$ Amphetamine is a white, odorless crystalline power that is swallowed, smoked, snorted or injected and is a highly addictive substance. ${ }^{20}$ Over the years, amphetamines have gained the reputation of being able to increase sexual desire, extend the sexual relation and making orgasm more intense. With longterm use of methamphetamine there is a decrease in dopamine $\mathrm{D}_{2}$ receptor availability in the caudate and putamen, and a decrease in metabolic rate in the orbitofrontal cortex ${ }^{54}$ and loss of dopamine transporters that is associated with motor and cognitive impairment. ${ }^{55}$

Prolonged use of amphetamine-based drugs has been associated with ED and delayed ejaculation in men. ${ }^{40}$ In addition, prolonged use of methamphetamine is strongly associated with a condition called "crystal dick" in which the user has a strong libido, high energy and lowered sexual inhibitions, but is unable to get penile erection. ${ }^{56}$ Jiann reported on 223 amphetamine mono- users with prevalence of $\mathrm{ED}$ of $34.5 \%$ and an OR of $\mathrm{ED}$ of 3.2 (95\% CI: $1.9 \sim 5.3$ ), compared to non-addict controls (Table 2)..$^{50}$

Table 2. Demographic data and prevalence of erectile dysfunction (ED) in heroin, amphetamine and MDMA mono-users

\begin{tabular}{|c|c|c|c|c|}
\hline & $\begin{array}{l}\text { Heroin mono-users } \\
\qquad(\mathrm{n}=276)\end{array}$ & $\begin{array}{l}\text { Amphetamine mono-users } \\
\qquad(\mathrm{n}=223)\end{array}$ & $\begin{array}{l}\text { MDMA mono-users } \\
\quad(n=62)\end{array}$ & $\begin{array}{l}\text { Non-addict controls } \\
\qquad(\mathrm{n}=196)\end{array}$ \\
\hline Age, years (range) & $36.8 \pm 7.6(19 \sim 61)$ & $32.9 \pm 7.9(18 \sim 53)$ & $26.2 \pm 6.0(18 \sim 54)$ & $35.4 \pm 5.6(24 \sim 54)$ \\
\hline Duration of abuse, months (range) & $27,5 \pm 44.2(0.5 \sim 240)$ & $25.4 \pm 46.2(0.1 \sim 252)$ & $4.6 \pm 7.6(0.5 \sim 42)$ & NA \\
\hline $\begin{array}{l}\text { Percentile of having dosing frequency } \\
\geq 3 \text { times per day, } \%\end{array}$ & 32.1 & 16.0 & 1.9 & NA \\
\hline Prevalence of ED, \% & 44.2 & 34.5 & 19.4 & 14.3 \\
\hline Odds ratio of ED (95\% Cl) & $4.8(2.9 \sim 7.8)$ & $3.2(1.9 \sim 5.3)$ & $1.4(0.6 \sim 3.2)$ & 1 \\
\hline \multicolumn{5}{|l|}{ Distribution of degree of ED*, \% } \\
\hline Mild & 16.7 & 13.9 & 11.3 & 5.6 \\
\hline Mild to moderate & 6.9 & 7.6 & 4.8 & 2.0 \\
\hline Moderate & 5.1 & 5.4 & 1.6 & 5.6 \\
\hline Severe & 15.6 & 7.6 & 1.6 & 1.0 \\
\hline
\end{tabular}

${ }^{*}$ Classified as mild ED if erectile function domain score of International Index of Erectile Function is 22 25; mild to moderate ED, 17 21: moderate ED, 11 16 and; severe ED, <11. $\chi^{2}$ test for distribution of degree of ED among heroin, amphetamine and MDMA users and controls, $p<0.05$; NA, not available. 


\section{3) MDMA}

MDMA or 3,4-methylenedioxymethamphetamine (MDMA) is a synthetic amphetamine, also known as XTC, E, Adam, MDM or "love drug". ${ }^{57}$ Its acute effects appear to be mediated by the release and reuptake inhibition of serotonin and dopamine. ${ }^{58}$ Dopamine has been implicated as facilitator and serotonin an inhibitor of sexual function. ${ }^{59,60}$ There are long-term psychiatric and physical problems associated with MDMA use. Neurotoxicity induced by MDMA is cumulative and is related to the dose and frequency of drug use. $^{61}$

Zemishlany et al. studied the subjective effects of MDMA and found that $40 \%$ of the subjects reported a negative effect on erectile function and $40 \%$ of them a positive effect. ${ }^{62}$ Buffum et al. reported that $46 \%$ of the MDMA users had decreased erectile ability. ${ }^{63}$ Jiann reported MDMA users did not have a significantly higher risk of ED, compared to controls (Table 2). ${ }^{50}$ The discrepancy may be attributed to that MDMA itself does not affect erectile function or that the dosing in the subjects was not adequate to induce ED because the MDMA users were relatively young in age and less addicted to it. ${ }^{50}$

\section{4) Cocaine}

Cocaine is found in the leaves of Erythroxylon coca, trees that are indigenous to Bolivia and Peru. Cocaine is a powerful central and peripheral nervous system stimulant that can be taken intranasally, injected intravenously or smoked (Table 1). In the brain, cocaine acts as a monoamine transporter blocker, with similar affinities for dopamine, serotonin, and norepinephrine transporters. ${ }^{64}$

Cocaine appears to have two opposite effects on sexuality according to its acute or choric abuse. New or infrequent cocaine users may report that cocaine induces spontaneous erection and ejaculation. ${ }^{65}$ However, other research reported that ambiguous findings of cocaine's impact on sexuality might be due to variation in the dosage, route of administration or other factors. ${ }^{66}$ MacDonald et al. found that of men who had used co- caine for 1 year or longer, $66 \%$ reported to have erection difficulties. ${ }^{67}$ With chronic abuse of cocaine, sexual dysfunction is attributed mainly to hyperprolactinemia and downregulation of the hypothalamic dopaminergic receptors. ${ }^{68}$ There are reports of cases of priapism associated with intracavernosal injection of cocaine. ${ }^{69}$

\section{5) Marijuana (Cannabinoids)}

Derived from the cannabis sativa plant, dela-9-tetrahydrocannabinol, the primary active ingredient in marijuana, produces sedation, mild euphoria and mild analgesia. ${ }^{40}$ Cannabinoids are generally inhaled by smoking, but may also be ingested. Cannabis derivatives are the most widely used illicit drugs in the world. ${ }^{70}$

In the most extensive study of the sexual effects of regular marijuana smoking, 70\% of male users reported that marijuana increased sexual pleasure and satisfactions. ${ }^{71}$ It is suggested that the enhancement of sexual experiences from marijuana use can be modulated by the expectations of users, personality type, age, consumption setting, and relationship status of the couple. ${ }^{19}$ The impact of long-term marijuana use on sexuality and sexual function is unclear as the very limited research on this topic has conflicting results. ${ }^{20}$

\section{Discussion}

The relationship between psychoactive substances and sexual behavior are complex, not always direct. Caution should be taken when interpreting research on the effects of drugs on sexual function. Psychological, physiological, environmental, or cultural factors may be associated with use of a particular substance, and may have independent or intervening effects on erectile function. ${ }^{40}$

There is a wide variation in the dosing frequency, amount and duration of drug abuse, as well as in the purity of substance that may influence the occurrence and severity of ED; but these factors were hardly taken consideration in the studies. Polydrug use is not uncommon in men with illicit drug abusers. In the study of 
701 illicit drug users, 92.5\% were active smokers, 6.6\% had alcoholism and $19.0 \%$ used more than one kind of illicit drugs. ${ }^{50}$ However, the synergic effect of polydrug use on ED is rarely investigated. Despite these limitations and knowledge gaps, the available research does suggest that alcohol, tobacco and illicit drugs have deleterious effects on men's erectile function. Virtually, alcohol and illicit drugs are known to have inhibitory effects on libido and ejaculation. ${ }^{40,50,60}$

Psychoactive substance dependence is a predominantly male activity. Illicit drug use is even more prevalent among young people than in older age groups. ${ }^{72}$ The telephone survey study (MATeS) in 6000 Australian men older than 40 yrs revealed that $80 \%$ of the respondents expressed concern about losing erectile function. ${ }^{73}$ This study indicates that younger men are more concerned about losing their ability to achieve an erection than older men. Sex issue always attracts more attention from media and general population. ED has already become a new weapon in the war on tobacco use and can be applied in the war on alcohol and illicit drug use too.

\section{References}

1. The world health report 2002: Reducing risks, promoting health life. World Health Organization:Geneva,2002.

2. Babor TF, Caetano R, Casswell S, Edwards G, Giesbrecht N, Graham $\mathrm{K}$, et al. Alcohol: no ordinary commodity-research and public policy. Oxford: Oxford University Press,2003.

3. $\mathrm{NIH}$ consensus conference. Impotence. $\mathrm{NIH}$ consensus development panel on impotence. JAMA 1993;270:83-90.

4. Burnett AL, Lowenstein CJ, Bredt DS, Chang TS, Snyder SH. Nitric oxide: a physiologic mediator of penile erection. Science 1992;257: 401-3.

5. Bredt DS, Hwang PM, Glatt CE, Lowenstein C, Reed RR, Snyder SH. Cloned and expressed nitric oxide synthase structurally resemble cytochrome P-450 reductase. Nature 1991;351:714-8.

6. Lyons CR, Orloff GJ, Cunningham JM. Molecular cloning and functional expression of an inducible nitric oxide synthase from a murine macrophage cell line. J Biol Chem 1992;267:6370-4.

7. Lamas S, Marsden PA, Li GK, Tempst P, Michel T. Endothelial nitric oxide synthase: molecular cloning and characterization of a distinct constitutive enzyme isoform. Proc Natl Acad Sci U S A 1992;89:634852.

8. Snyder SH, Jaffrey SR. Vessels vivified by Akt acting on NO synthase. Nat Cell Biol 1999;1:E95-6.
9. Dimmeler S, Fleming I, Fisslthaler B, Hermann C, Busse R, Zeiher AM. Activation of nitric oxide synthase in endothelial cells by Akt-dependent phosphorylation. Nature 1999;399:601-5.

10. McVary KT, Carrier S, Wessells H, Subcommittee on Smoking and Erectile Dysfunction Socioeconomic Committee, Sexual Medicine Society of North America. Smoking and erectile dysfunction: evidence based analysis. $J$ Urol 2001;166:1624-32.

11. Adachi H, Sato Y, Kato R, Hisasue S, Suzuki K, Masumori N, et al. Direct evidence of facilitative actions of dopamine in the medial preoptic area on reflexive and noncontact erections in male rats. $J$ Urol 2003;169:386-9.

12. Holmes GM, Bresnahan JC, Beattie MS. Inhibition of pudendal reflexes in spinal rats. Reassessing the role of serotonin. Physiol Behav 2001;74:57-64

13. Traish A, Kim N. The physiological role of androgens in penile erection: regulation of corpus cavernosum structure and function. $J$ Sex Med 2005;2:759-70.

14. Meinhardt W, Kropman RF, Vermeij P, Nijeholt AA, Zwartendijk J. The influence of medication on erectile function. Int $J$ Impot Res 1997;9:17-26.

15. Pollack MH, Reiter S, Hammerness $P$, Genitourinary and sexual adverse effects of psychotropic medication. Int J Psychiatry Med 1992; 22:305-27.

16. Horowitz JD, Goble AJ. Drugs and impaired male sexual function. Drugs 1979;18:206-17.

17. Mirin SM, Meyer RE, Mendelson JH, Ellingboe J. Opiate use and sexual function. Am J Psychiatry 1980;137:909-15.

18. Millar JG. Drug-induced impotence. Practitioner 1979;223:634-9.

19. Rosen RC. Alcohol and drug effects on sexual response: human experimental and clinical studies. Ann Rev Sex Res 1991;2:119-79.

20. McKay A. Sexuality and substance use: the impact of tobacco, alcohol and selected recreational drugs on sexual function. Can J Hum Sex 2005;14:47-56.

21. Jacobs MR, Fehr KOB. Drugs and drug abuse: a reference text. 2nd ed. Toronto: Addiction Research Foundation,1987.

22. McBride WJ. Central nucleus of the amygdala and the effects of alcohol and alcohol-drinking behavior in rodents. Pharmacol Biochem Behav 2002;71:509-15.

23. Grobin AC, Matthews DB, Devaud LL, Morrow AL. The role of GABA(A) receptors in the acute and chronic effects of ethanol. Psychopharmacology (Berl) 1998;139:2-19.

24. Wang GJ, Volkow ND, Franceschi D, Fowler JS, Thanos PK, Scherbaum $\mathrm{N}$, et al. Regional brain metabolism during alcohol intoxication. Alcohol Clin Exp Res 2000;24:822-9.

25. Nordmann R, Ribière $\mathrm{C}$, Rouach $\mathrm{H}$. Ethanol-induced lipid peroxidation and oxidative stress in extrahepatic tissues. Alcohol 1990;25:231-7.

26. Rivier C, Rivest S, Vale W. Alcohol-induced inhibition of LH secretion in intact and gonadectomized male and female rats: possible mechanisms. Alcohol Clin Exp Res 1992;16:935-41.

27. O'Farrell TJ, Kleinke CL, Cutter HS. Sexual adjustment of male alcoholics: changes from before to after receiving alcoholism counseling with and without marital therapy. Addict Behav 1998;23:419-25.

28. Mandell W, Miller CM. Male sexual dysfunction as related to alcohol consumption: a pilot study. Alcohol Clinic Exp Res 1983;7:65-9.

29. Snyder S, Karacan I. Effects of chronic alcoholism on nocturnal penile tumescence. Psychosom Med 1981;43:423-9. 
30. Fahrner EM. Sexual dysfunction in male alcohol addicts: prevalence and treatment. Arch Sex Behav 1987;16:247-57.

31. Lemere F, Smith JW. Alcohol-induced sexual impotence. Am J Psychiatry 1973;130:212-3.

32. Mackay J, Eriksen M. The tobacco atlas. World Health Organization: Geneva,2002

33. Foulds J, Stapleton JA, Bell N, Swettenham J, Jarvis MJ, Russell MA. Mood and physiological effects of subcutaneous nicotine in smokers and never-smokers. Drug Alcohol Depend 1997;44:105-15.

34. Sullivan ME, Keoghane SR, Miller MA. Vascular risk factors and erectile dysfunction. BJU Int 2001;87:838-45.

35. Wolf R, Shulmam A. Erectile dysfunction and fertility related to cigarette smoking. J Eur Acad Dermatol Venereol 1996;6:209-16.

36. Tengs TO, Osgood ND. The link between smoking and impotence: two decades of evidence. Prev Med 2001;32:447-52.

37. Feldman HA, Johannes CB, Derby CA, Kleinman KP, Mohr BA, Araujo $\mathrm{AB}$, et al. Erectile dysfunction and coronary risk factors: prospective results from the Massachusetts male aging study. Prev Med 2000;30:328-38

38. Bortolotti A, Fedele D, Chatenoud L, Colli E, Coscelli C, Landoni M, et al. Cigarette smoking: a risk factor for erectile dysfunction in diabetics. Eur Urol 2001;40:392-6.

39. Mirone V, Imbimbo C, Bortolotti A, Di Cintio E, Colli E, Landoni $\mathrm{M}$, et al. Cigarette smoking as a risk for erectile dysfunction: results from an Italian epidemiological study. Eur Urol 2002;41:294-7.

40. Peugh J, Belenko S. Alcohol, drugs and sexual function: a review. J Psychoactive Drugs 2001;33:223-32.

41. Donatucci CF, Lue TF. Erectile dysfunction in men under 40: etiology and treatment choice. Int J Impot Res 1993;5:97-103.

42. Palha AP, Esteves M. A study of the sexuality of opiate addicts. $J$ Sex Marital Ther 2002;28:427-37.

43. Brownstein MJ. A brief history of opiates, opioid peptides and opioid receptors. Proc Natl Acad Sci U S A 1993;90:5391-3.

44. Jaffe JH. Drug addiction and drug abuse. In: Gilman AG, Rall TW, Njes AS, Taylor P, eds. Goodman and Gilman's the pharmacological basis of therapeutics. 8th ed. New York: Pergamon Press,1990;522-73.

45. Mansour A, Fox CA, Akil H, Watson SJ. Opioid-receptor mRNA expression in the rat CNS: anatomical and functional implications. Trends Neurosci 1995;18:22-9.

46. Pasternak GW. Pharmacological mechanisms of opioid analgesics. Clin Neuropharmacol 1993;16:1-18.

47. Jaffe JH, Knapp CM, Ciraulo DA. Opiates: clinical aspects in: Lowinson JH, Ruiz P, Millman RB, Langrod JG, eds. Substance abuse: a comprehensive textbook: 3rd ed. Baltimore, Maryland: Williams \& Willkins,1997.

48. Cushman P Jr. Sexual behavior in heroin addiction and methadone maintenance. Correlation with plasma luteinizing hormone. N Y State J Med 1972;72:1261-5.

49. Mintz J, O'Hare K, O'Brien CP, Goldschmidt J. Sexual problems of heroin addicts. Arch Gen Psychiatry 1974;31:700-3.

50. Bang-Ping J. Sexual dysfunction in men who abuse illicit drugs: a preliminary report. J Sex Med 2007.

51. Roberts L, Finch PM, Pullan PT, Bhagat CI, Price LM. Sex hormone suppression by intrathecal opioids: a prospective study. Clin J Pain 2002;18:144-8.

52. Smith DE, Moser C, Wesson DR, Apter M, Buxton ME, Davison JV, et al. A clinical guide to the diagnoses and treatment of heroin-related sexual dysfunction. J Psychoactive Drugs 1982;14:91-9.

53. Hallinan R, Byrne A, Agho K, McMahon C, Tynan P, Attia J. Erectile dysfunction in men receiving methadone and buprenorphine maintenance treatment. $J$ Sex Med 2008;5:684-92.

54. Volkow ND, Chang L, Wang GJ, Fowler JS, Ding YS, Sedler M, et al. Low level of brain dopamine D2 receptors in methamphetamine abusers: association with metabolism in the orbitofrontal cortex. Am J Psychiatry 2001;158:2015-21.

55. Volkow ND, Chang L, Wang GJ, Fowler JS, Leonido-Yee M, Franceschi D, et al. Association of dopamine transporter reduction with psychomotor impairment in methamphetamine abusers. Am J Psychiatry 2001;158:377-82.

56. Hirshfiled S, Remien RH, Walavalkar I, Chiasson MA. Crystal methamphetamine use predicts incident STD infection among men who have sex with men recruited online: a nested case-control study. $J$ Med Internet Res 2004;6:e41.

57. Shaper AG. Walking on the moon. Lancet 1996;347:207-8.

58. Steele TD, McCann UD, Ricaurte GA. 3,4-methylenedioxymethamphetamine (MDMA , "Ecstasy"): pharmacology and toxicology in animals and humans. Addiction 1994;89:539-51.

59. Schiavi RC, Segraves RT. The biology of sexual function. Psychiatr Clin North Am 1995;18:7-23.

60. Palha AP, Esteves M. Drugs of abuse and sexual functioning. Adv Psychosom Med 2008;29:131-49.

61. Kalant H. The pharmacology and toxicology of "ecstasy" (MDMA) and related drugs. CMAJ 2001;165:917-28.

62. Zemishlany Z, Aizenberg D, Weizman A. Subjective effects of MDMA ('Ecstasy') on human sexual function. Eur Psychiatry 2001;16:127-30.

63. Buffum J, Moser C. MDMA and human sexual function. $J$ Psychoactive Drugs 1986;18:355-9.

64. Ritz MC, Cone EJ, Kuhar MJ. Cocaine inhibition of ligand binding at dopamine, norepinephrine and serotonin transporters: a structureactivity study. Life Sci 1990;46:635-45.

65. Buffum J. Pharmacolosexology: the effects of drugs on sexual function: a review. J Psychoactive Drugs 1982;14:5-44.

66. Buffum J, Moser C, Smith D. Street drugs and sexual function. In: Sisten JMA, ed. Handbook of sexology. Volume 6: the pharmacology and endocrinology of sexual function. New York: Elsevier Science Publishers,1988.

67. MacDonald PT, Waldorf D, Reinarman C, Murphy S. Heavy cocaine use and sexual behavior. J Drug Issues 1988;18:437-55.

68. Saso L. Effects of drug abuse on sexual response. Ann Ist Super Sanità 2002;38:289-96.

69. Mireku-Boateng AO, Tasie B. Priapism associated with intracavernosal injection of cocaine. Urol Int 2001;67:109-10.

70. Adams IB, Martin BR. Cannabis: pharmacology and toxicology in animals and humans. Addiction 1996;91:1585-614.

71. Halikas J, Weller R, Morse C. Effects of regular marijuana use on sexual performance. J Psychoactie Drugs 1982;14:59-70.

72. UNODCCP Global illicit drug trends. New York, NY, United Nations Office for Drug Control and Crime Prevention,2002.

73. Holden GA, McLachlan RI, Pitts M, Cumming R, Wittert G, Agius PA, et al. Men in Australia Telephone Survey (MATeS): a national survey of the reproductive health and concerns of middle-aged and older Australian men. Lancet 2005;366:218-24. 